\title{
Spinodal decomposition of Ni-Nb-Y metallic glasses
}

\author{
N. Mattern ${ }^{*}, 1$, G. Goerigk ${ }^{2}$, U. Vainio ${ }^{3}$, M.K. Miller ${ }^{4}$, T. Gemming ${ }^{1}$, and J. Eckert ${ }^{1}$ \\ ${ }^{1}$ Leibniz-Institute IFW Dresden, Institute for Complex Materials, P.O. Box 270116, \\ D-01171 Dresden, Germany \\ ${ }^{2}$ Institute for Solid State Research, Forschungszentrum Jülich, P.O. Box 1913, 52425 Jülich, \\ Germany \\ ${ }^{3}$ HASYLAB at DESY, Notkestr. 85, D-22603 Hamburg, Germany \\ ${ }^{4}$ Oak Ridge National Laboratory, Oak Ridge,TN 37831-6136, U.S.A.
}

Keywords: phase separation, metallic glass, spinodal decomposition, small angle scattering

\begin{abstract}
Phase-separated Ni-Nb-Y metallic glasses were prepared by rapid quenching from the melt. The early stages of decomposition were characterized in Ni-Nb-Y alloys with $\mathrm{Ni}$ contents of more than 60 at.\%. Strongly correlated chemical fluctuations with a nanometer length scale were found to exist in the as-quenched state. The observed fluctuation lengths range from 5 to $12 \mathrm{~nm}$ depending on the actual composition of the glass. The "frozen-in" early stages of decomposition occur in the deeply undercooled melt due to the reduction of the critical temperature of liquid-liquid phase separation with the Ni content. Annealing of the phase separated $\mathrm{Ni}_{70} \mathrm{Nb}_{15} \mathrm{Y}_{15}$ glass below the crystallization temperature leads to an increase of the amplitude of the fluctuations. However, the wavelength was unchanged which gives evidence of the spinodal character of the decomposition.
\end{abstract}

${ }^{*}$ Corresponding author. tel.:+49 3514659 367: fax: +49 3514659452

e-mail address: n.mattern@ifw-dresden.de 


\section{Introduction}

Decomposition and phase separation in the equilibrium liquid below the critical temperature $T_{c}\left(T_{c}>T_{\text {liquidus }}\right)$ is known for several binary phase diagrams with strong positive enthalpy of mixing of the components like e.g. Nb-Y, Al-In, and Pb-Al [1]. For binary alloy systems like $\mathrm{Co}-\mathrm{Cu}[2]$ and $\mathrm{Fe}-\mathrm{Cu}$ [3] with small positive enthalpy of mixing, a miscibility gap exists in the metastable undercooled liquid below the liquidus temperature $\left(\mathrm{T}_{\mathrm{c}}<\mathrm{T}_{\text {liquidus }}\right)$. Upon passing the critical temperature during cooling, the melt decomposes into two liquids. These decomposed regions then grow. In alloy systems with high glass-forming ability, the decomposed liquids can be frozen into a phase separated glass by rapid quenching techniques like melt spinning. This behaviour has been well known in some oxide glass systems for more than 50 years [4]. The first phase separated metallic glass was probably prepared in the Zr-YAl-Ni system by Inoue et al. in 1994 [5]. In 2004, Kündig et al. reported two-phase glassy alloys in the $\mathrm{Zr}-\mathrm{La}-\mathrm{Al}-\mathrm{Ni}-\mathrm{Cu}$ system [6]. In the following years, phase separated metallic glasses were successfully prepared in several alloy systems: Zr-Y-Co-Al [7], Ni-Nb-Y [8], ZrNd-Al-Co [9], Cu-(Zr,Hf)-(Gd,Y)-Al [10], and Zr-(Ce,Pr,Nd)-Al-Ni [11]. In all these cases, phase separation leads to a special microstructure with a length-scale up to several micron and some self similar features are observed by transmission electron microscopy (TEM)[6,12,13]. All these materials reported so far represent frozen-in late states which have passed spinodal decomposition and growth of the melts by diffusion and coalescence as well as secondary precipitations reactions. The microstructure formed depends on the thermodynamic and kinetic properties of the alloy system as well as the cooling rate.

In this paper, the formation and transformation of early stages of phase-separated glasses in the Ni-Nb-Y system with fluctuations on the length scale of only several nanometers are reported. The aim of this work is to analyze the behaviour of the decomposition in deeply undercooled Ni-Nb-Y liquids. 


\section{Experimental}

Pre-alloyed ingots were prepared by arc-melting elemental $\mathrm{Ni}, \mathrm{Nb}$ and $\mathrm{Y}$ with purities of $99.9 \%$ or higher in a Ti-gettered argon atmosphere. To ensure homogeneity, the samples were remelted several times. From these pre-alloys, thin ribbons $(3 \mathrm{~mm}$ in width and $30 \mu \mathrm{m}$ in thickness) with nominal compositions $\mathrm{Ni}_{66} \mathrm{Nb}_{17} \mathrm{Y}_{17}, \mathrm{Ni}_{68} \mathrm{Nb}_{16} \mathrm{Y}_{16}$, and $\mathrm{Ni}_{70} \mathrm{Nb}_{15} \mathrm{Y}_{15}$ were prepared by single-roller melt spinning under argon atmosphere. The casting temperature was $1923 \mathrm{~K}$. The chemical compositions were determined by the titration technique. The resulting values were $\mathrm{Ni}_{66.1} \mathrm{Nb}_{17.6} \mathrm{Y}_{16.3}, \mathrm{Ni}_{67.9} \mathrm{Nb}_{17.3} \mathrm{Y}_{14.8}$, and $\mathrm{Ni}_{71.3} \mathrm{Nb}_{13.7} \mathrm{Y}_{15.0 \text {, }}$, respectively for the asprepared ribbons. These compositions exhibit only slight deviations from the nominal value of up to $\sim 1$ at. $\%$. For convenience, the nominal compositions are used in the following sections. X-ray diffraction (XRD) patterns were recorded in Bragg-Brentano geometry with CoK $\alpha$ radiation using a Panalytical X'Pert Pro diffractometer. TEM was performed with a FEI Tecnai F30. For the TEM investigations, the ribbons were thinned by Ar ion milling at an accelerating voltage of $2.5 \mathrm{keV}$ under a grazing incidence angle of $4^{\circ}$.

The three-dimensional structure of the material was determined using atom probe tomography (ATP) with an Imago Scientific Instruments laser-pulsed local electrode atom probe. Anomalous small angle X-ray scattering (ASAXS) was measured with the JUSIFA beam line [14] at the DORIS storage ring at HASYLAB/DESY Hamburg. The measurements were performed with four X-ray energies in the vicinity of the K-absorption edge of $\mathrm{Ni}$ at $8333 \mathrm{eV}$. Background measurements took 15 min followed by measurements of a calibration standard (glassy carbon, $5 \mathrm{~min}$ ) and subsequent measurements of the sample frames (15 min). This measurement cycle was repeated for the four different energies. The measurements were performed at two sample-detector distances (935 and $3635 \mathrm{~mm}$ ) covering a q-range between 0.05 and $6.0 \mathrm{~nm}^{-1}$. After the completion of the ASAXS measurements at four energies, the complete cycle of four energies was repeated four times for accumulation of intensity. In total for the samples and the background measurements a beam time of $1 \mathrm{~h}$ and for the related 
reference measurements a beam time of 20 min was accumulated. This strategy was used in numerous publications emerging from the JUSIFA beam line in the last decade [15-17] and compromises between the goal of accumulating sufficient scattering intensity (reducing the statistical error bars of the scattering curves) and reducing the influence of the significant beam instabilities of DORIS ( $2^{\text {nd }}$ generation) as much as possible. The scattering curves are calibrated into macroscopic scattering cross sections via the reference measurements in units of cross section per unit volume $\left[\mathrm{cm}^{2} / \mathrm{cm}^{3}\right]=\left[\mathrm{cm}^{-1}\right]$. A heating stage under vacuum was used for in-situ measurements.

\section{Experimental results}

The XRD patterns of as-quenched and annealed $\mathrm{Ni}_{70} \mathrm{Nb}_{15} \mathrm{Y}_{15}$ ribbons are shown in Figure 1. The diffuse character of the scattering curve for all the as-quenched alloys indicates the amorphous state. The amorphous structures were also confirmed by high resolution TEM and local electron diffraction. A typical high resolution TEM image of the rapidly quenched $\mathrm{Ni}_{70} \mathrm{Nb}_{15} \mathrm{Y}_{15}$ ribbon is shown in Figure 2. Similar results were observed for the as-quenched state of the other two alloys. The microstructure appears homogeneously in the bright field images.

The spatial distribution of the solute in the rapidly quenched $\mathrm{Ni}_{68} \mathrm{Nb}_{16} \mathrm{Y}_{16}$ alloy was investigated by ATP. A Y atom map of a selected volume with lengths $a=20 \mathrm{~nm}, \mathrm{~b}=20 \mathrm{~nm}$, and $\mathrm{c}=5 \mathrm{~nm}$, viewed parallel to the c-direction is shown in Figure 3. Regions with higher or lower Y-concentrations can be clearly seen. The $\mathrm{Nb}$ and $\mathrm{Y}$ concentrations from a 4 x $4 \mathrm{~nm}$ cross section concentration profile through the volume are shown in Figure 4. Fluctuations with $\sim 5-10 \mathrm{~nm}$ length in the $\mathrm{Y}$ and $\mathrm{Nb}$ content well above of the statistical noise are clearly visible. The opposed $\mathrm{Nb}$ and $\mathrm{Y}$ concentrations point to the existence of $\mathrm{Nb}$ - and $\mathrm{Y}$-enriched clusters, as observed for rapidly quenched Ni-Nb-Y alloys with lower Ni content $(<60$ at.\%) $[8,13]$. These data prove the presence of chemical inhomogeneities in the rapidly quenched 
sample. In accordance with the TEM data, a much smaller extent of the inhomogeneities is observed for the glassy alloys with higher Ni contents, which also have smaller differences in chemical composition.

In contrast to the atom probe tomography data, X-ray small angle scattering provides integral information on existing inhomogeneities in electron density with a size ranging from the nanometer up to the micron range. The calibrated small angle X-ray scattering (SAXS) curves $d \sigma / d \Omega(q)$ ( $q$ is the magnitude of the scattering vector, $q=4 \pi \sin \theta / \lambda$, scattering angle $2 \theta$, wavelength $\lambda$ ) depend on differences in electron density, but also on the volume fraction, size, and shape of the inhomogeneities built up from the different phases [19]:

$$
\frac{d \sigma}{d \Omega}(\vec{q})=\int \widetilde{\rho}^{2}(\vec{r}) \exp (i \vec{q} \vec{r}) d^{3} r
$$

where $\widetilde{\rho}^{2}(\vec{r})$ represents the so-called auto-correlation function, which is calculated from the spatial distribution of the electron scattering-length density $\rho(r)$ [14a]. The scattering length can be tuned by variation of the energy at the X-ray absorption edges of the involved elements which is explored for anomalous small angle Xray-scattering (ASAXS) [20,21]. In the case of an isotropic structure, the scattering curves averaged over all orientations are given by [19]:

$$
\frac{d \sigma}{d \Omega}(q)=\int 4 \pi \cdot r^{2} \tilde{\eta}^{2}(r) \frac{\sin (q r)}{q r} d r
$$

where $\tilde{\eta}^{2}(r)=\widetilde{\rho}(r)^{2}-V \rho_{0}{ }^{2}$ is the square of the so-called electron density fluctuation $\eta(r)=\rho(r)-\rho_{0}$, which is calculated from the difference of the electron scattering-length density $\rho(r)$ and the average electron scattering-length density $\rho_{0}$ in the sample volume $V$. The SAXS curves $d \sigma / d \Omega(q)$ of the three samples measured at the energy $E=8291 \mathrm{eV}, 42 \mathrm{eV}$ below the Ni-K edge are shown in Figure 5. For comparison, the measurement of a binary $\mathrm{Ni}_{59.5} \mathrm{Nb}_{40.5}$ glass is also given. The homogeneous $\mathrm{Ni}-\mathrm{Nb}$ glass shows almost no small angle 
scattering for $q>0.2 \mathrm{~nm}^{-1}$. The increasing intensity below $q<0.2 \mathrm{~nm}^{-1}$ probably originates from surface scattering also present in the $\mathrm{Ni}-\mathrm{Nb}-\mathrm{Y}$ data. In contrast, the $\mathrm{Ni}-\mathrm{Nb}-\mathrm{Y}$ glasses show weak contribution in the SAXS data for $q>0.2 \mathrm{~nm}^{-1}$. The curves give clear evidence for the existence of correlated fluctuations in electron density for the $\mathrm{Ni}-\mathrm{Nb}-\mathrm{Y}$ alloys. Variation of the energy at the $\mathrm{Y}$ - and Nb-edges changes the cross section of the SAXS curves in opposite directions indicating that the inhomogeneities are related to clusters enriched in $\mathrm{Y}$ or in $\mathrm{Nb}$ in agreement with the atom probe tomography results [22]. The occurrence of the maximum in the SAXS curves is due to the high density of electron density fluctuations with a dominant correlation length. Obviously, the correlation length $\zeta$ varies with the Ni content. The shift of the position of the maximum with composition from $q_{\max }=0.5$ to $1.2 \mathrm{~nm}^{-1}$ indicates a reduction of $\zeta$ with increasing Ni content. Using the relationship correlation length $\zeta$ and peak maximum in reciprocal distances $\zeta=2 \pi / q_{\max }$ one obtains $\zeta=12 \mathrm{~nm}$ for $\mathrm{Ni}_{66} \mathrm{Nb}_{17} \mathrm{Y}_{17}, \zeta=8 \mathrm{~nm}$ for $\mathrm{Ni}_{68} \mathrm{Nb}_{16} \mathrm{Y}_{16}$, and $\zeta=5 \mathrm{~nm}$ for $\mathrm{Ni}_{70} \mathrm{Nb}_{15} \mathrm{Y}_{15}$. Eq.(2) can be solved numerically using the concentration curve $c(z)$ experimentally determined by the atom probe tomography (Fig. 3). The calculated small angle scattering $I(q)$ of the $\mathrm{Ni}_{68} \mathrm{Nb}_{17} \mathrm{Y}_{17}$ alloy in comparison with the experimental data is shown in Figure 5. The general shape of the curve with a maximum of $\sim 0.8 \mathrm{~nm}^{-1}$ is in a good agreement with the experimental SAXS data. The increase of the intensity for $q<0.6 \mathrm{~nm}^{-1}$ is caused by the termination error due to the limited size of the data from the APT slab of $70 \mathrm{~nm}$. Assuming an oscillating concentration profile by a simple function $\mathrm{c}(\mathrm{r})=\cos (2 \pi r / \zeta) * \exp \left(-0.05^{*} r\right) \quad(\zeta=8 \mathrm{~nm}, \mathrm{r}=0-200 \mathrm{~nm})$, the calculated SAXS curve exhibits the correlation peak at the same position as shown in Fig.5 (a rdependent damping was applied to reduce the termination error).

The decomposition state of the rapidly quenched glassy $\mathrm{Ni}-\mathrm{Nb}-\mathrm{Y}$ alloys is also suggested by the crystallization upon heating. Each of the amorphous phases or clusters crystallizes separately at a distinct temperature, as indicated by the DSC traces shown in Figure 6. The first exothermic event is related to the crystallization of the Ni-Y-rich glassy 
phase as can be seen by the XRD pattern of the $\mathrm{Ni}_{70} \mathrm{Nb}_{15} \mathrm{Y}_{15}$ samples after heating in the DSC, as shown in Figure 1. The small size of the amorphous clusters leads to a corresponding nanometer-size of the formed $\mathrm{Ni}_{2} \mathrm{Y}$-phase. The XRD pattern of $\mathrm{Ni}_{70} \mathrm{Nb}_{15} \mathrm{Y}_{15}$ heated to $823 \mathrm{~K}$, i.e. above the first DSC event, (Fig.1) exhibits strong broadening of the reflections. An average crystallite size of $5 \mathrm{~nm}$ is estimated from the widths at half maximum by applying the Scherrer equation. The amorphous $\mathrm{Ni}-\mathrm{Nb}$ phase crystallizes at higher temperature indicated by the second exothermic DSC event. Along with the formation of the $\mathrm{Ni}_{3} \mathrm{Nb}$ phase, coarsening of all other phases also takes place, as proven by the decrease of the width of the XRD reflections in Figure1.

Annealing below the crystallization temperature does not measurably change the XRD pattern. In order to analyze the behaviour of the decomposition in the undercooled liquid state, in-situ ASAXS measurements were performed at elevated temperatures. The $\mathrm{Ni}_{70} \mathrm{Nb}_{15} \mathrm{Y}_{15}$ alloy was chosen because the SAXS curve of the as-quenched state exhibits only a rather small distinct maximum. Patterns recorded during isothermal annealing at $\mathrm{T}=723 \mathrm{~K}$ well below the crystallization temperature $\left(\mathrm{T}_{\mathrm{x}-\mathrm{onset}}=755 \mathrm{~K}\right)$ are shown in Figure 7 . For comparison the data of the sample at room temperature before heating are also given (circles). With increasing time, the height or integral intensity of the maximum enlarges. The maximum position $q_{\max }=1.2 \mathrm{~nm}^{-1}$ remains unchanged during the heat treatment. A similar behaviour is observed for an other sample measured at $\mathrm{T}=748 \mathrm{~K}$. The integral intensities of the SAXS curves as a function of time are shown in Figure 8. It can be seen from the semi-logarithmic plot that the intensity increases exponentially in the early stages. At later stages the growth diminishes and converges to a stationary stage. Both SAXS curves can be transformed into each other by a scaling factor describing the same thermally activated process of decomposition. As expected, a higher decomposition rate is found for the in-situ measurement performed at the higher temperature. The retention of the amorphous state of the samples during heat treatment was proven by subsequent XRD measurements of the annealed samples. 
The corresponding patterns without any trace of crystallization are also included in Figure 1. According to the SAXS intensities possible crystallization should lead to an increase of intensity maxima above the detection limit of the XRD method, which is not the case. Furthermore, the reduction of the slope of SAXS intensity with time is in contradiction with a primary crystallization of the samples.

\section{Discussion}

The microstructure formation during rapid quenching is related to the phase diagram and the phase separation in the undercooled melt. The decomposition and phase separation of the liquid in the binary $\mathrm{Nb}-\mathrm{Y}$ system extends to large $\mathrm{Ni}$ contents in the ternary $\mathrm{Ni}-\mathrm{Nb}-\mathrm{Y}$ liquid [18]. A pseudo-binary section of the ternary phase diagram along the line $\mathrm{Ni}-\mathrm{Ni}_{50} \mathrm{Nb}_{25} \mathrm{Y}_{25}$ is shown in Figure 9. The miscibility gap in the liquid $\left(\mathrm{L}_{1}+\mathrm{L}_{2}\right)$ exists up to $\sim 60$ at.\% Ni The critical temperature $T_{C}$ decreases with increasing Ni content. The extrapolation of the critical temperature $T_{C}$ for higher $\mathrm{Ni}$ content $>60$ at. $\%$ as given by the triangles is also depicted in Figure 9. For the alloys with higher $\mathrm{Ni}$ content, the phase separation proceeds in the metastable undercooled liquid at much lower temperatures. Lower temperature means slower kinetics of decomposition and growth after the phase separation. Furthermore, less time is required to reach the glass transition temperature $T_{g}$ where the undercooled liquids become frozen into the glass. Therefore, early stages of decomposition are obtained by rapid quenching for the glasses with higher Ni contents.

The structure formation by spinodal decomposition is usually described by the CahnHillard theory [23]. The decomposition is initiated via the spontaneous formation and subsequent growth of coherent composition fluctuations. An exponential time law is derived for the scattered intensity from the linear Cahn-Hillard theory which is in agreement with the observed dependence of $I(q)$ during early stages of annealing the $\mathrm{Ni}_{70} \mathrm{Nb}_{15} \mathrm{Y}_{15}$ glass. Binder et 
al. [24] showed that this mean field theory is in contrast with quantitative results of experiments as well as molecular dynamics simulations. Several reasons for the discrepancies are given, like nonlinear effects, relaxation, coupling between variables. At later stages the stationary state of the amplitude is reached and the composition profile may change into a square-like shape which gives reason for the deviation from the exponential growth of the SAXS intensity [25]. Also coarsening of the fluctuation may occur resulting in a shift of the SAXS maximum to lower $q$-values [24]. In the experimental SAXS data (Fig. 7), the position of the maximum of $I(q)$ does not change. This means that for the $\mathrm{Ni}_{70} \mathrm{Nb}_{15} \mathrm{Y}_{15}$ glass the fluctuation length remains constant during the decomposition process. This behaviour points to spinodal decomposition as mechanism in $\mathrm{Ni}-\mathrm{Nb}-\mathrm{Y}$ glasses. The observed variation in fluctuation length with the Ni-content (Fig. 5) is determined by the alloy composition but not by the quenching conditions. The differences in heights of the maximum of $I(q)$ of the different $\mathrm{Ni}-\mathrm{Nb}-\mathrm{Y}$ glasses is probably related to the increase of the critical temperature for lower Ni-contents. Due to increased temperature difference between $T_{c}$ and $T_{g}$ for $\mathrm{Ni}_{68} \mathrm{Nb}_{16} \mathrm{Y}_{16}$ and $\mathrm{Ni}_{66} \mathrm{Nb}_{17} \mathrm{Y}_{17}$, the amplitudes of the concentration fluctuations start to grow already during the quenching.

\section{Conclusions}

Phase separated metallic glasses can be prepared in the Ni-Nb-Y system by rapid quenching from the melt. For Ni contents $>60$ at.\% early stages of decomposition can be obtained. The fluctuation length varies between 5 and $12 \mathrm{~nm}$ depending on the composition. Annealing at elevated temperatures in the deeply undercooled liquid state leads to an increase of the amplitude of the fluctuation leaving the wavelength constant pointing to spinodal decomposition. Further investigation with improved ASAXS possibilities are expected to give experimental data for a better understanding of the spinodal decomposition in metallic glasses. 


\section{$\underline{\text { Acknowledgements }}$}

Valuable discussions with H. Hermann and W. Löser are gratefully acknowledged. The authors thank S. Donath, B. Bartusch, A. Ostwaldt, and B. Arnold for technical support. The authors thank the Leibniz-society for financial support within the framework "Pakt für Forschung". Research at the Oak Ridge National Laboratory SHaRE User Facility was sponsored by the Scientific User Facilities Division, Office of Basic Energy Sciences, U.S. Department of Energy.

\section{References}

[1] Massalski TB, (Ed.) “Binary Alloy Phase Diagrams” ASM International 1990.

[2] Nakagawa Y, Acta Metall.1958; 6:704.

[3] Elder SP, Munitz A, Abbaschian GJ, Mater. Sci. Forum 1989;50:137.

[4] Vogel W, „Glaschemie“, Springer, Berlin, 1992.

[5] Inoue A, Chen S, Masumoto T Mater. Sci. Eng. A 1994;179/180: 346.

[6] Kündig AA, Ohnuma M, Ping DH, Ohkubo T, Hono K, Acta Mater. 2004; 52: 2441.

[7] Park BJ, Chang HJ, Kim DH, Kim WT, Appl. Phys. Lett. 2004; 85: 6353.

[8] Mattern N, Kühn U, Gebert A, Gemming T, Zinkevich M, Wendrock H, Schultz L, Scripta Mater. 2005; 53: 271.

[9] Park ES, Jeong EY, Lee JK, Kwon AR, Gebert A, Schultz L, Chang HJ, Kim DH, Scripta Mater. 2007; 56 :197.

[10] Park ES, Kyeong JS, Kim DH, Scripta Mater. 2007; 57: 49.

[11] Wada,T, Louzguine-Luzgin D, Inoue A, Scripta Mater. 2007; 57: 901

[12] Park BJ, Chang HJ, Kim DH, Kim WT, Chattopadhyay K, Abindanan TA, Bhattacharyya S, Phys.Rev. Lett. 2006; 6: 245503.

[13] Mattern N, Gemming T, Goerigk G, Eckert J, Scripta Mater. 2007; 57 : 29. 
[14] Haubold HG, Gruenhagen K, Wagener M, Jungbluth H, Heer H, Pfeil A, Rongen H,

Brandenburg G, Moeller R, Matzerath J, Hiller P, Halling H, Rev. Sci. Instrum. 1989; 60:1943.

[15] Goerigk G, Schweins R, Huber K, Ballauff M, Europhys. Lett. 2004; 66 (3):331.

[16] Goerigk G, Williamson DL, J. Appl. Phys. 2006; 99: 084309.

[17] Bota A, Varga Z, Goerigk G, J. Phys. Chem. C 2008; 112 (12): 4427.

[18] Mattern N, Zinkevich M, Löser W, Behr G, Acker J, J. Phase Equil. Diff. 2008; 29: 141.

[19] Glatter O, Kratky O,” Small-Angle X-ray Scattering”, 1982; Academic Press, London

[20] Stuhrmann H.B, Goerigk G, Munk B. (1991): In: Ebashi, S., Koch, M., Rubenstein, E. (eds.) Handbook of Synchrotron Radiation, Elsevier, Amsterdam,1991; Vol. 4: 555.

[21] Goerigk G, Haubold HG, Lyon O, Simon JP, J. Appl. Cryst. 2003; 36: 425.

[22] Goerigk G, Mattern N, in preparation

[23] Cahn JW, Hillard JE, J. Chem. Phys. 1959; 31:539. , J .Chem. Phys, 1959; 31:688.

[24] Binder K, Fratzl P, "Spinodal Decomposition" in "Phase Transformations in Material" ed. G. Kostorz, Wiley-VHC, Weinheim, 2001; p.409-480.

[25] Tsakalakos T, Dugan, MP, J.Mat.Science 1985;20:1301. 


\section{$\underline{\text { Figure captions }}$}

Fig. 1: XRD pattern of as-quenched $\mathrm{Ni}_{66} \mathrm{Nb}_{17} \mathrm{Y}_{17}, \mathrm{Ni}_{68} \mathrm{Nb}_{16} \mathrm{Y}_{16}, \mathrm{Ni}_{70} \mathrm{Nb}_{15} \mathrm{Y}_{15}$, and annealed $\mathrm{Ni}_{70} \mathrm{Nb}_{15} \mathrm{Y}_{15}$ samples ( $\mathrm{Si}$ powder was added to one sample as internal standard for lattice parameter determination)

Fig. 2: Transmission electron microscopy image and electron diffraction pattern of the asspun $\mathrm{Ni}_{68} \mathrm{Nb}_{16} \mathrm{Y}_{16}$ ribbon.

Fig. 3: Spatial distribution of $Y$-atoms of rapidly quenched. $\mathrm{Ni}_{68} \mathrm{Nb}_{16} \mathrm{Y}_{16}$ (edge sizes of $20 \mathrm{~nm}$ $\mathrm{x} 20 \mathrm{~nm}$ and thickness of $5 \mathrm{~nm}$ )

Fig. 4: Concentration distribution $\mathrm{c}(\mathrm{z})$ of $\mathrm{Nb}$ and $\mathrm{Y}$ along a $4 \mathrm{~nm} \times 4 \mathrm{~nm} \times 40 \mathrm{~nm}$ slab.

Fig. 5 : SAXS curves $d \sigma / d \Omega(q)$ of glassy Ni-Nb-Y alloys and calculated data.

Fig. 6 : DSC trace of glassy Ni-Nb-Y alloys at a heating rate of $20 \mathrm{~K} / \mathrm{min}$.

Fig. 7 : In-situ SAXS $d \sigma / d \Omega(q)$ of $\mathrm{Ni}_{70} \mathrm{Nb}_{15} \mathrm{Y}_{15}$ glass after different times at $\mathrm{T}=723 \mathrm{~K}$.

Fig. 8: Integral intensity of the maximum of the SAXS curves at elevated temperatures vs. time.

Fig. 9 : Section of the ternary phase diagram $\mathrm{Ni}_{75} \mathrm{Nb}_{12.5} \mathrm{Y}_{12.5}-\mathrm{Ni}_{50} \mathrm{Nb}_{25} \mathrm{Y}_{25}$ with extrapolation (triangles) of the critical temperature $T_{c}$ (critical temperatures of the $\mathrm{Ni}-\mathrm{Nb}-\mathrm{Y}$ alloys are indicated by arrows) 
Figure1

Click here to download high resolution image

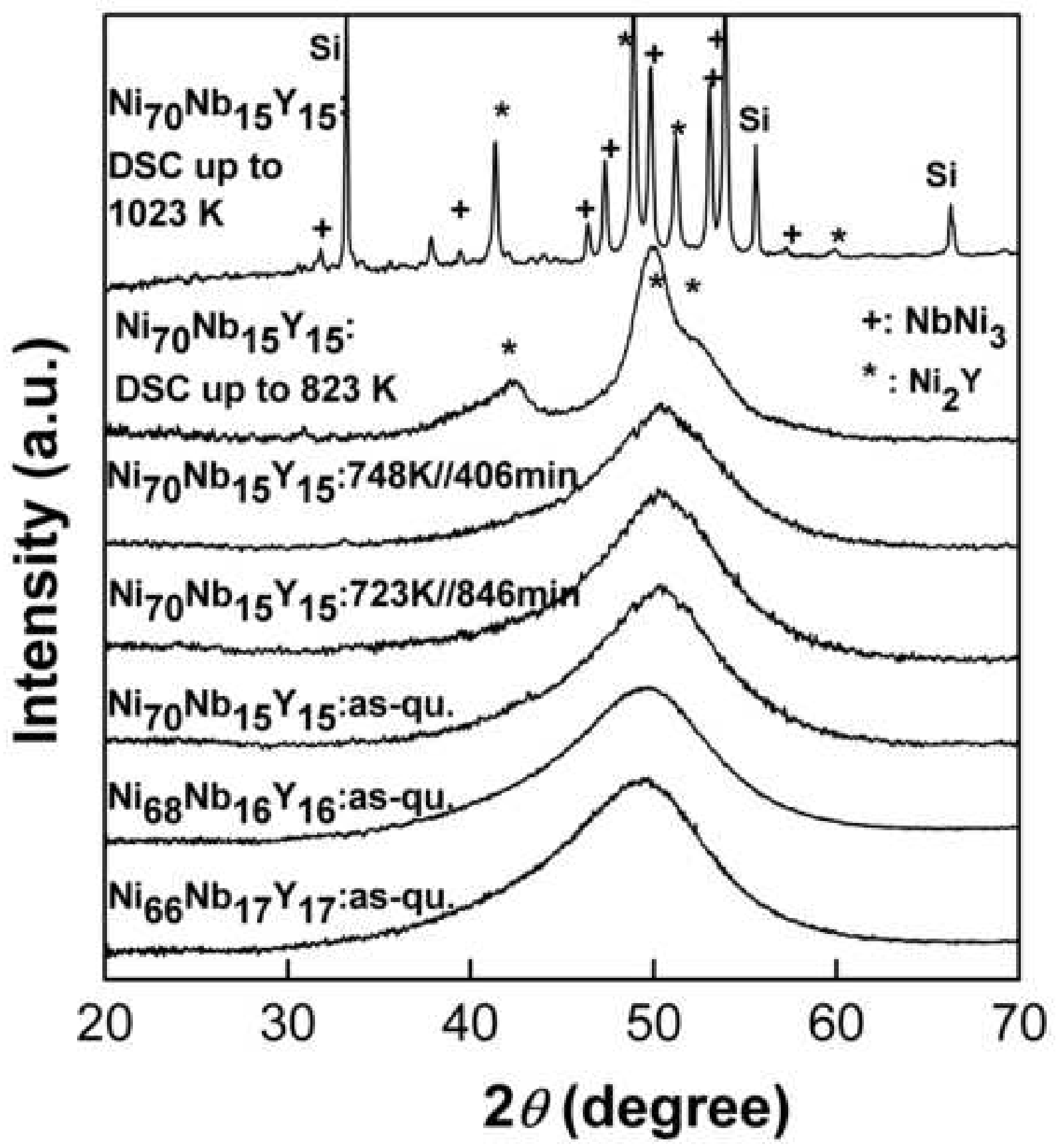


Click here to download high resolution image

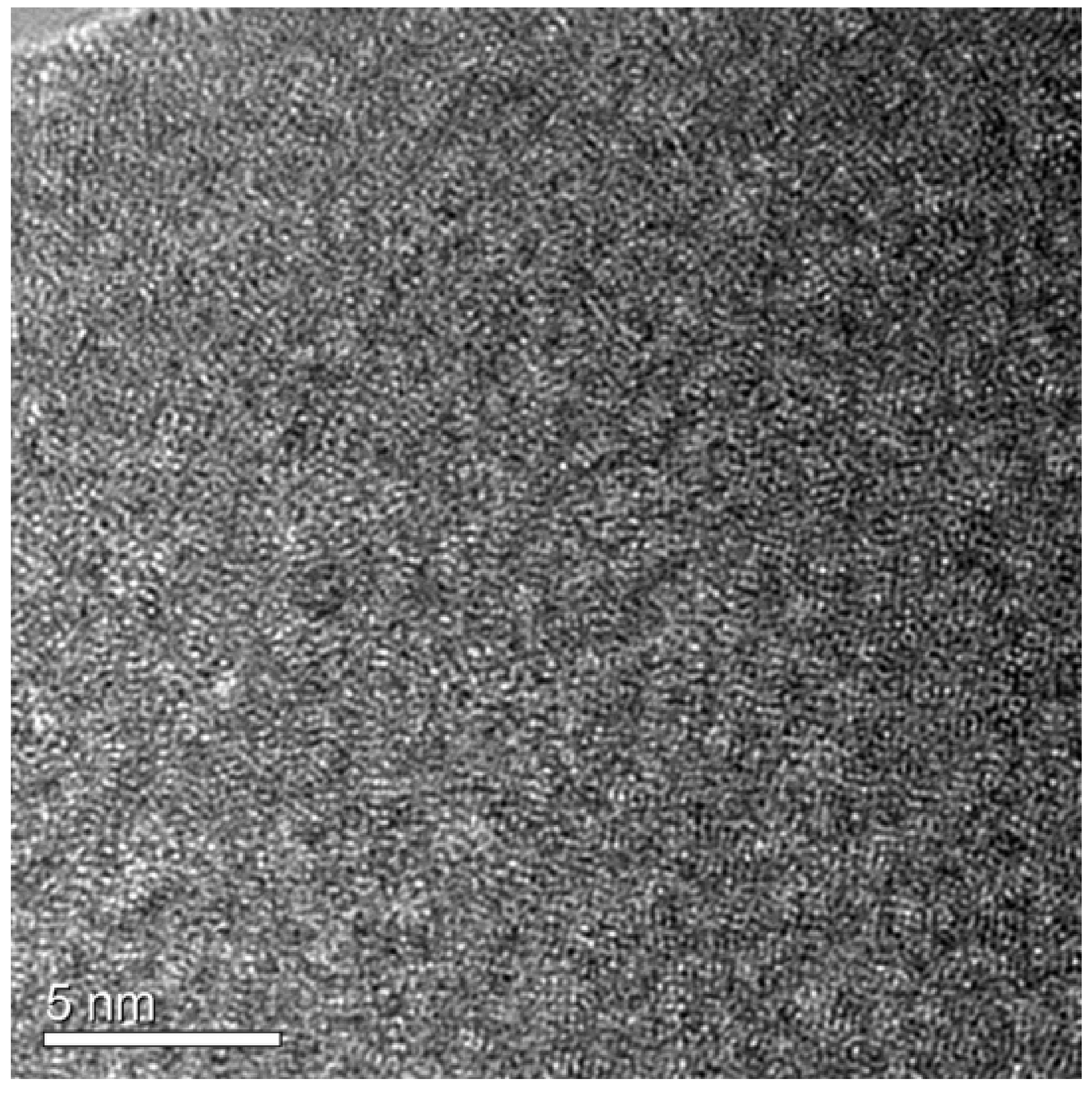

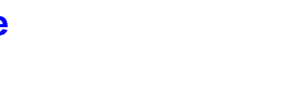

.

\section{.} . . .

\section{.} .

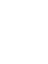

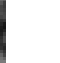

.

.

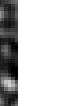
.

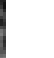

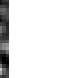
. .

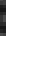

.

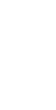

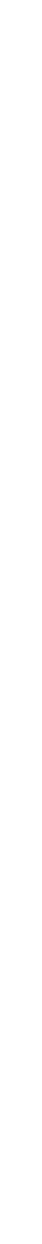



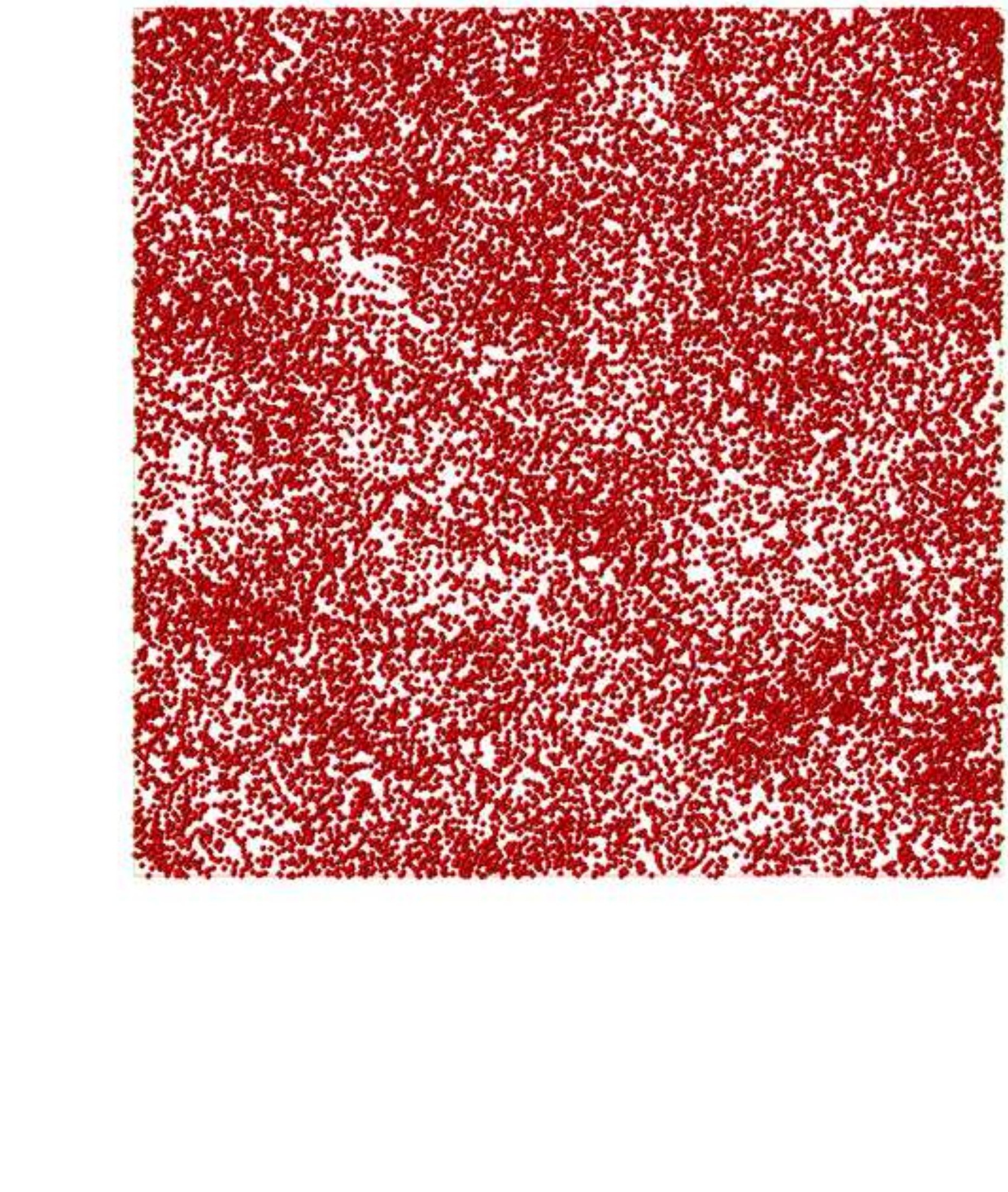


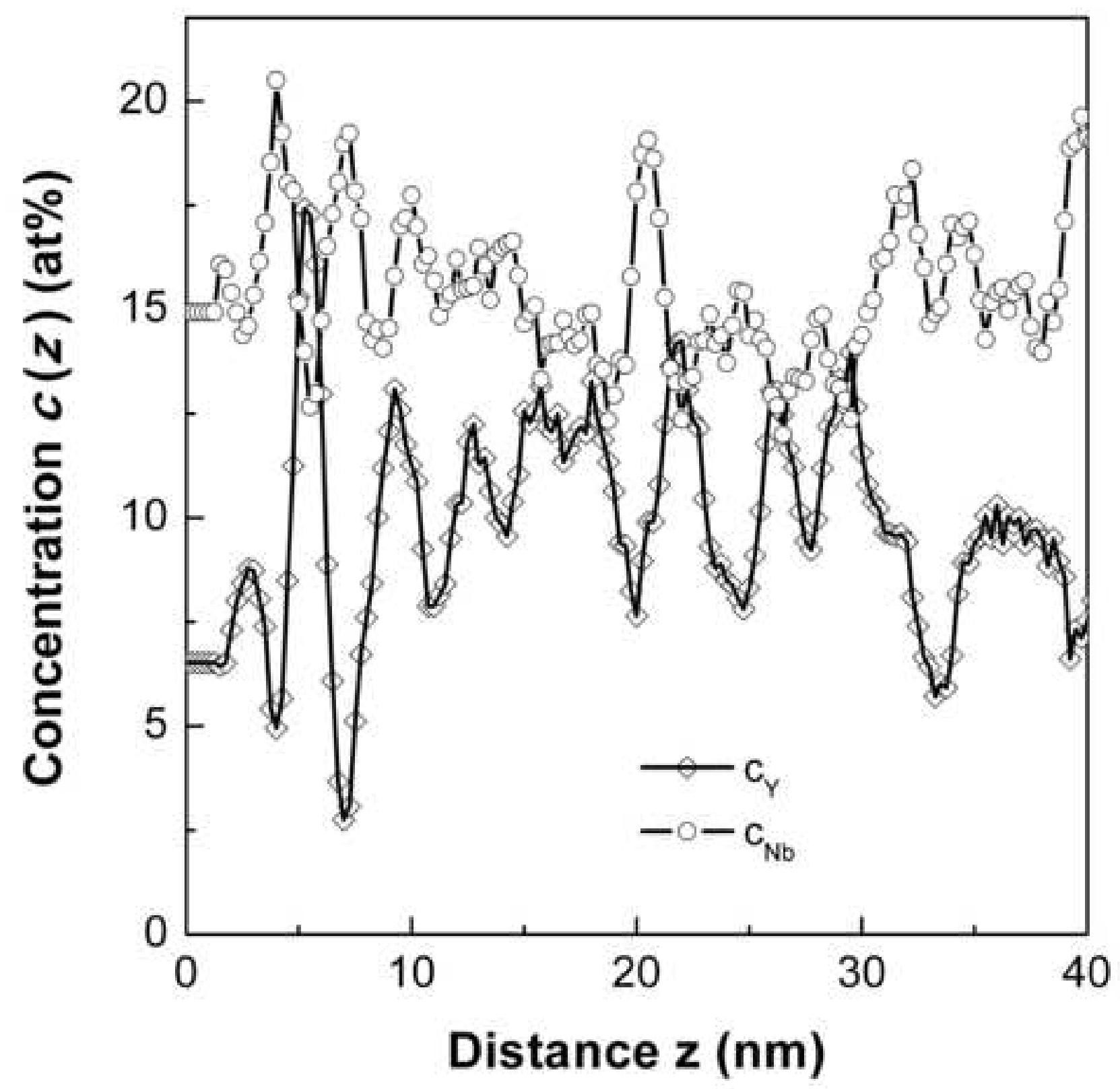




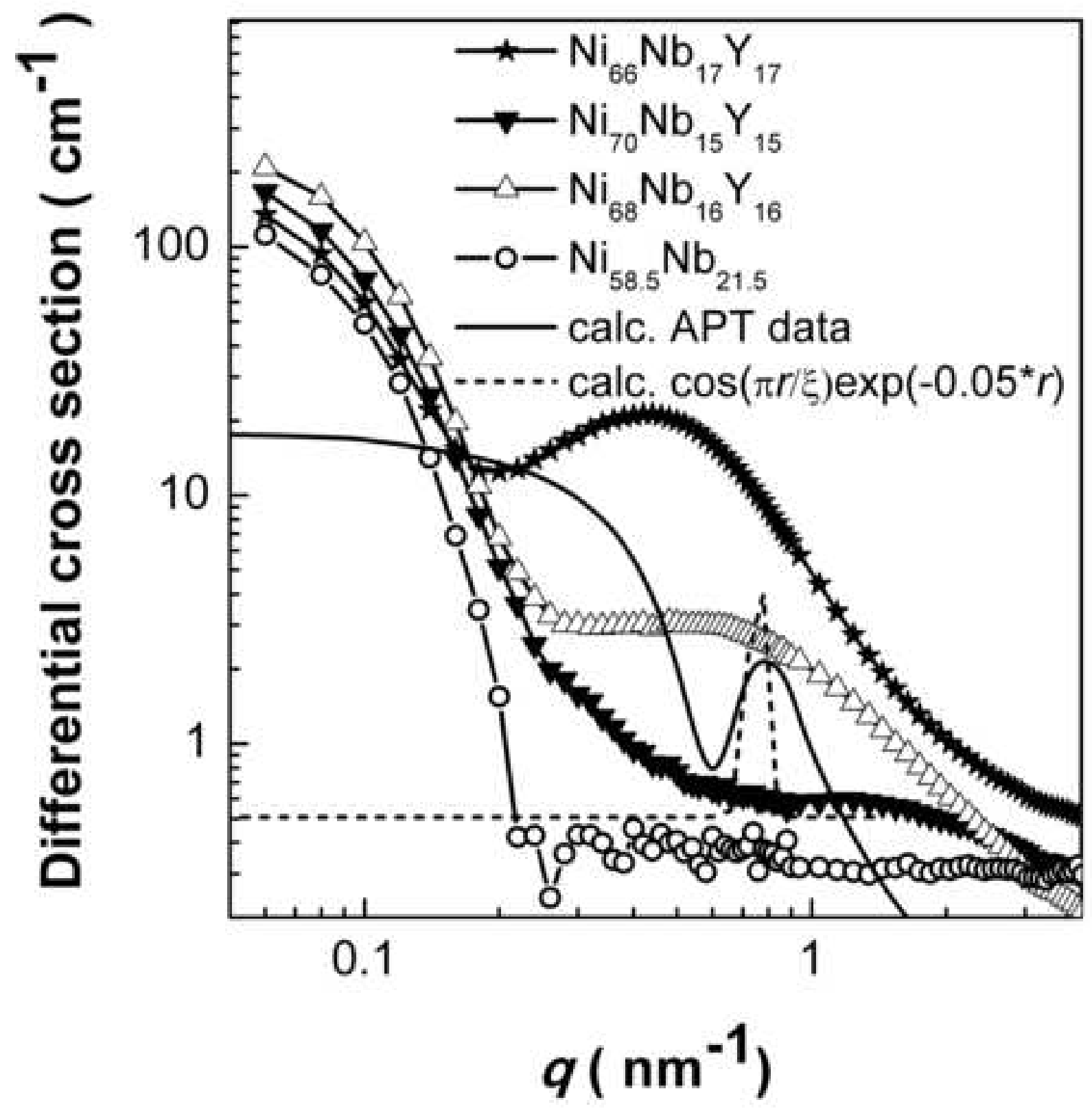


Figure6

Click here to download high resolution image

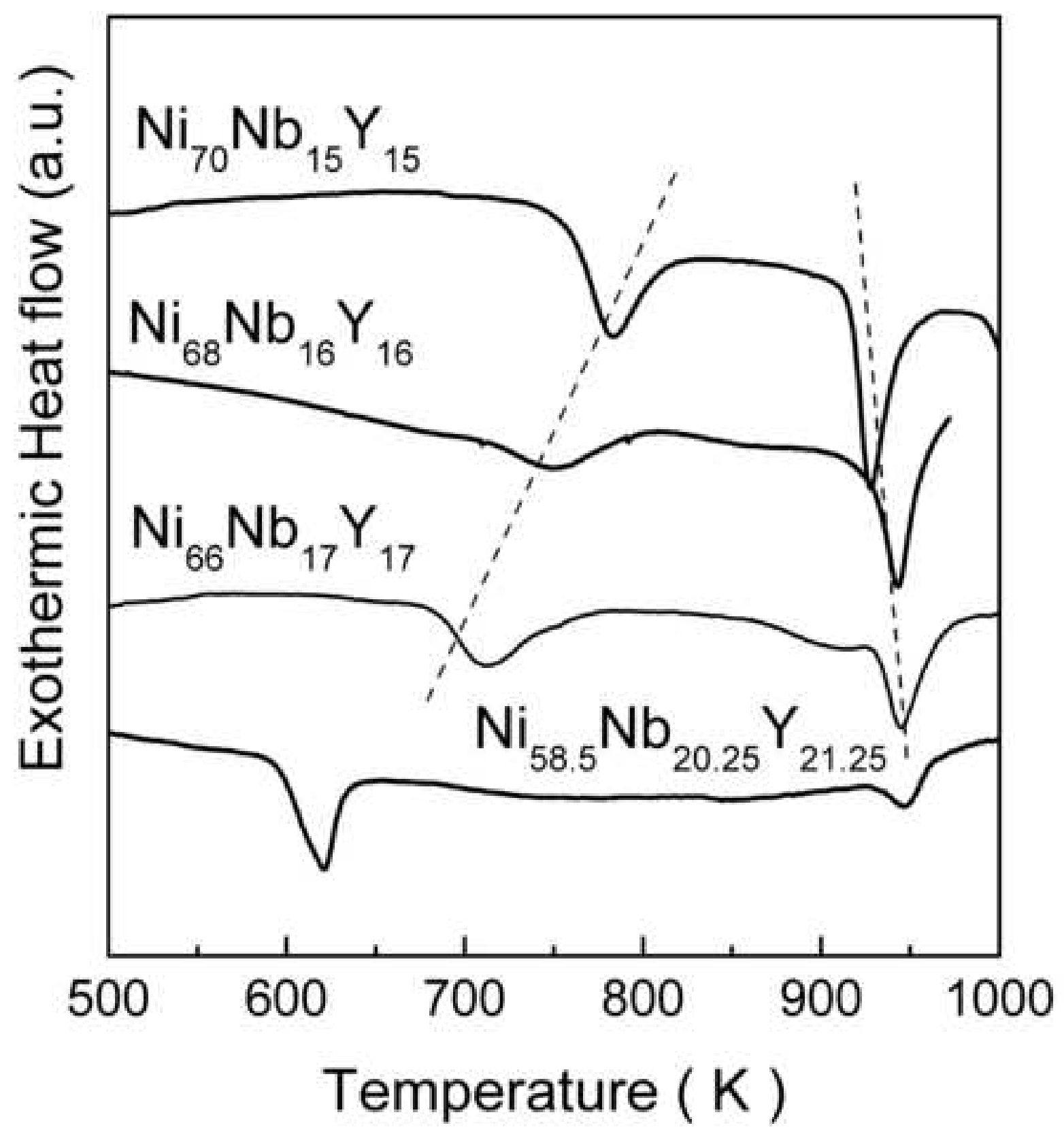


Figure7

Click here to download high resolution image

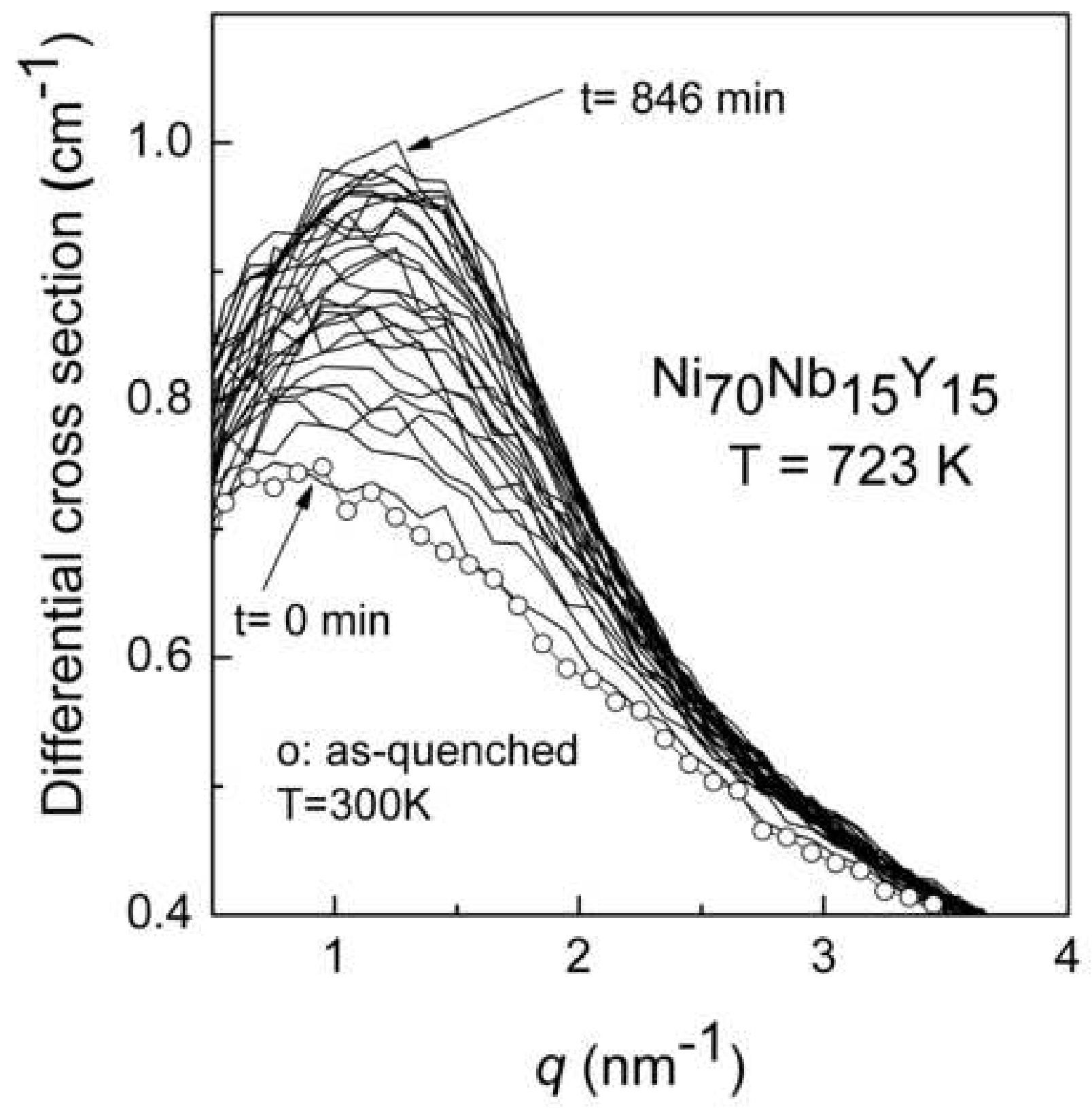


Figure
Click here to download high resolution image

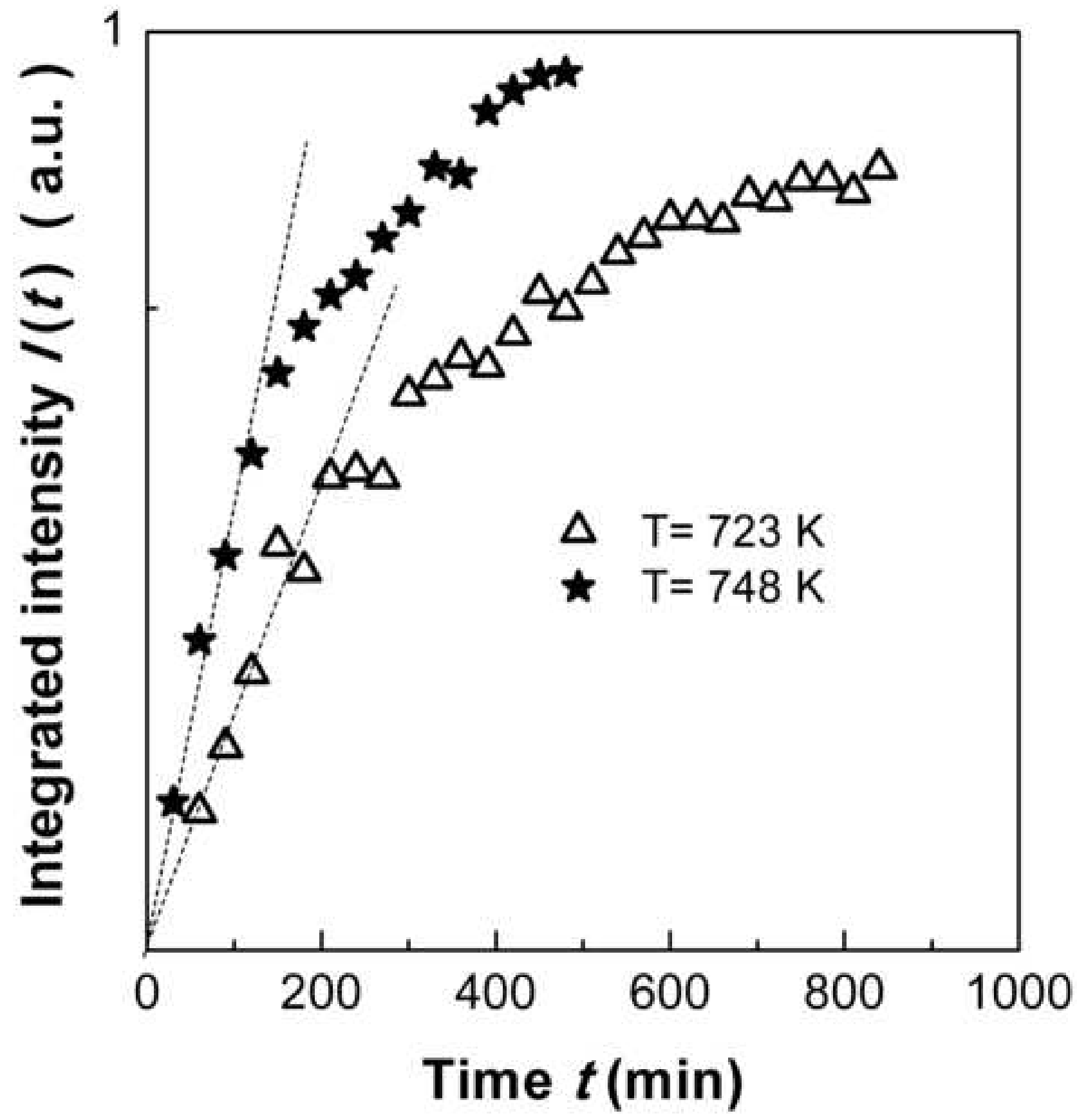




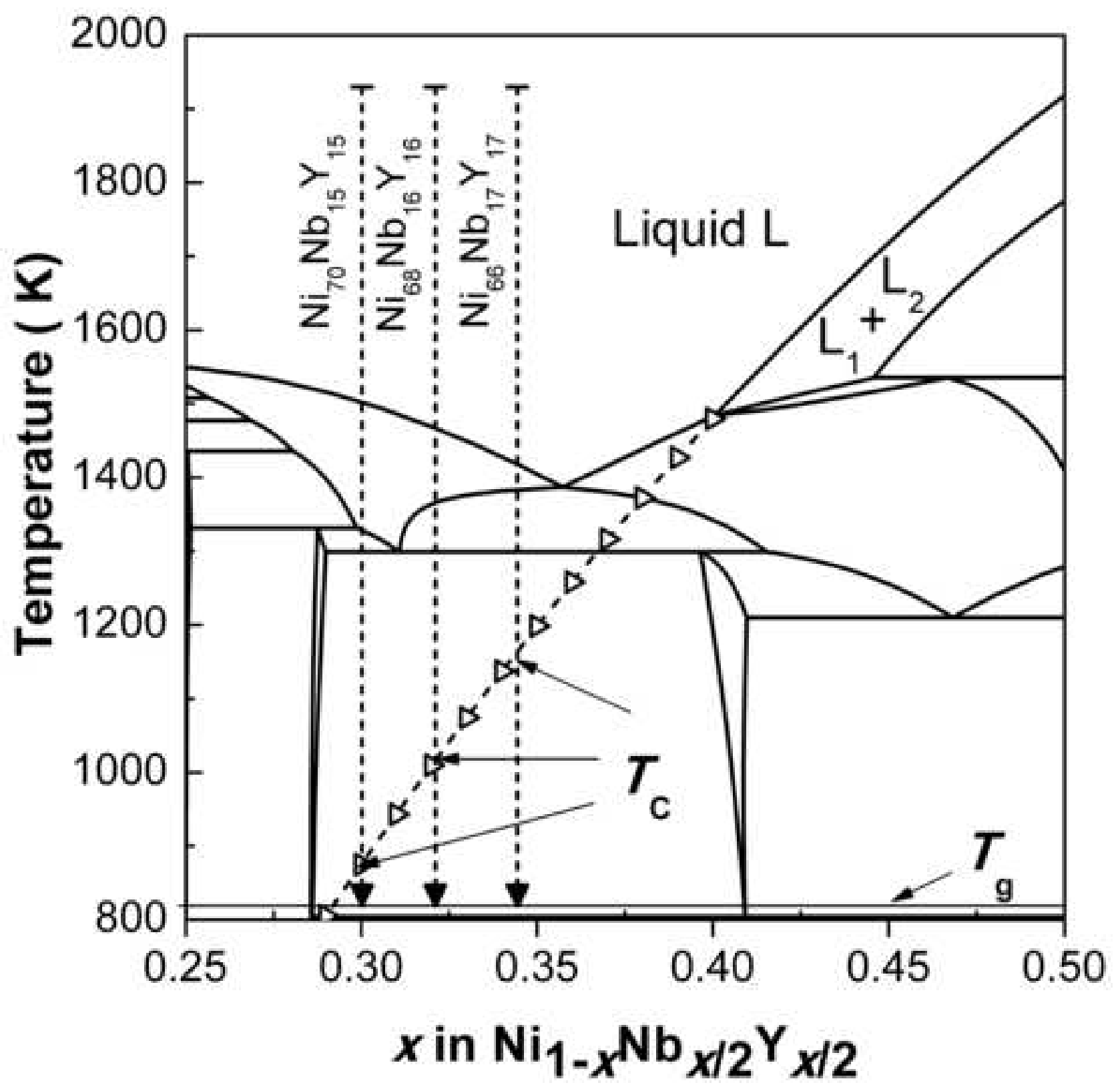

